\title{
Exposure of Rats to Multiple Oral Doses of Dichloroacetate Results in Upregulation of Hepatic Glutathione Transferases and NAD(P)H Dehydrogenase [Quinone] $1^{\text {[s }}$
}

\author{
Edwin J. Squirewell, Ricky Mareus, Lloyd P. Horne, Peter W. Stacpoole, and @ Margaret O. James \\ Departments of Medicinal Chemistry (E.J.S., R.M., M.O.J.), Medicine (L.P.H., P.W.S.), and Biochemistry and Molecular Biology \\ (P.W.S.), University of Florida, Gainesville, Florida
}

Received June 12, 2020; accepted August 11, 2020

\begin{abstract}
Dichloroacetate (DCA) is an investigational drug that is used in the treatment of various congenital and acquired disorders of energy metabolism. Although DCA is generally well tolerated, some patients experience peripheral neuropathy, a side effect more common in adults than children. Repetitive DCA dosing causes downregulation of its metabolizing enzyme, glutathione transferase zeta 1 (GSTZ1), which is also critical in the detoxification of maleylacetoacetate and maleylacetone. GSTZ1 (-/-) knockout mice show upregulation of glutathione transferases (GSTs) and antioxidant enzymes as well as an increase in the ratio of oxidized glutathione (GSSG) to reduced glutathione (GSH), suggesting GSTZ1 deficiency causes oxidative stress. We hypothesized that DCA-mediated depletion of GSTZ1 causes oxidative stress and used the rat to examine induction of GSTs and antioxidant enzymes after repeated DCA exposure. We determined the expression of alpha, mu, pi, and omega class GSTs, NAD(P)H dehydrogenase [quinone] 1 (NQO1), gamma-glutamylcysteine ligase complex (GCLC), and glutathione synthetase (GSS). GSH and GSSG levels were measured by liquid chromatography-tandem mass spectrometry. Enzyme activity was measured in hepatic cytosol using 1-chloro-2,4-dinitrobenzene, 1,2-dichloro-4-nitrobenzene, and 2,6-dichloroindophenol as substrates. In comparison with
\end{abstract}

acetate-treated controls, DCA dosing increased the relative expression of GSTA1/A2 irrespective of rodent age, whereas only adults displayed higher levels of GSTM1 and GSTO1. NQ01 expression and activity were higher in juveniles after DCA dosing. GSH concentrations were increased by DCA in adults, but the GSH:GSSG ratio was not changed. Levels of GCLC and GSS were higher and lower, respectively, in adults treated with DCA. We conclude that DCA-mediated depletion of GSTZ1 causes oxidative stress and promotes the induction of antioxidant enzymes that may vary between age groups.

\section{SIGNIFICANCE STATEMENT}

Treatment with the investigational drug, dichloroacetate (DCA), results in loss of glutathione transferase zeta 1 (GSTZ1) and subsequent increases in body burden of the electrophilic tyrosine metabolites, maleylacetoacetate and maleylacetone. Loss of GSTZ1 in genetically modified mice is associated with induction of glutathione transferases and alteration of the ratio of oxidized to reduced glutathione. Therefore, we determined whether pharmacological depletion of GSTZ1 through repeat administration of DCA produced similar changes in the liver, which could affect responses to other drugs and toxicants.
Glutathione transferases (GSTs) are a superfamily of enzymes that catalyze the conjugation of glutathione (GSH) to electrophilic sites of drugs, xenobiotics, and endogenous molecules. This represents an important mechanism of elimination, as the glutathione conjugates are converted to mercapturic acids for excretion. GSTs are drugmetabolizing enzymes, and the deactivation and detoxication of reactive molecules constitutes another important physiologic function of GSTs. GSTs are upregulated in response to oxidative stress (Hayes and McLellan, 1999; Hayes et al., 2005) and protect against lipid peroxidation (Hubatsch et al., 1998; Yang et al., 2001; Singh et al.,

This work was supported in part by the US Public Health Service [RO1-GM 099871].

https://doi.org/10.1124/dmd.120.000143.

S This article has supplemental material available at dmd.aspetjournals.org.
2015). Additionally, GSTs are involved in the synthesis of steroid hormones (Johansson and Mannervik, 2001) and promote cell signaling and proliferation (Laborde, 2010). Although generally cytoprotective, certain GSTs show higher expression in cancer cells relative to normal cells (Gaté and Tew, 2001; Hayes et al., 2005), and their overexpression has been associated with the development of anticancer drug resistance (Townsend and Tew, 2003; Pljesa-Ercegovac et al., 2018). This suggests that overexpression of GSTs may not always be beneficial.

Glutathione transferase zeta 1 (GSTZ1)/maleylacetoacetate isomerase is key in tyrosine catabolism and is responsible for detoxication of its two endogenous substrates, maleylacetoacetate (MAA) and maleylacetone (MA) (Blackburn et al., 1998; Li et al., 2011). GSTZ1 is also important in the metabolism of dichloroacetate (DCA) (Tong et al., 1998a,b), a byproduct of drinking water chlorination with clinical utility as an inhibitor of pyruvate dehydrogenase kinase (James et al., 2017;

ABBREVIATIONS: CDNB, 1-chloro-2,4-dinitrobenzene; DCA, dichloroacetate; DCNB, 1,2-dichloro-4-nitrobenzene; DCPIP, 2,6-dichlorophenolindophenol; GCLC, glutamylcysteine ligase complex; GSH, glutathione; GSS, glutathione synthetase; GSSG, oxidized glutathione; GST, glutathione transferase; GSTZ1, glutathione transferase zeta 1; LC-MS, liquid chromatography-mass spectrometry; MA, maleylacetone; MAA, maleylacetoacetate; NBD-Cl, 7-chloro-4-nitrobenzo-2-oxa-1,3-diazole; NQO1, NAD(P)H dehydrogenase [quinone] 1; PDC, pyruvate dehydrogenase complex; PDK, pyruvate dehydrogenase kinase; PPAR $\alpha$, peroxisome proliferator-activated receptor alpha; ROS, reactive oxygen species. 
Stacpoole et al., 2019). The pharmacodynamics of DCA originates in mitochondria, where DCA inhibits pyruvate dehydrogenase kinase (PDK) to maintain catalytic activity of the pyruvate dehydrogenase complex (PDC) (James and Stacpoole, 2016; Stacpoole et al., 2019), which stimulates mitochondrial oxidative phosphorylation. As such, DCA has been used as an investigative drug for the treatment of number of disorders of mitochondrial energy metabolism, including congenital PDC deficiency, diabetes, cancer, and pulmonary arterial hypertension (Michelakis et al., 2008; Kankotia and Stacpoole, 2014; James and Stacpoole, 2016; Stacpoole et al., 2018).

Chronic use of DCA is limited by the development of reversible peripheral neuropathy, a side effect more common in adults than children (Kaufmann et al., 2006; Stacpoole et al., 2019). Children metabolize DCA more quickly than adults (Mangal et al., 2018), although cause(s) for the age-dependent side effect of long-term DCA therapy remains unclear. DCA is a mechanism-based inactivator of GSTZ1 (Tzeng et al., 2000; Lantum et al., 2003; Smeltz et al., 2019), resulting in both inhibition of DCA metabolism and isomerization of MAA and MA with repetitive DCA dosing. The tissue accumulation of DCA, MAA, and MA, due to the DCA-mediated inactivation of GSTZ1, may be a mechanism responsible for DCA toxicity, as MAA and MA are alkylating agents (Cornett et al., 1999; Lantum et al., 2002). DCA dosing in rats resulted in increased concentrations of malondialdehyde and 4hydroxynonenal in sciatic nerves (Calcutt et al., 2009), which might also contribute to the neuropathology of DCA.

Studies in $\operatorname{GSTZ1}(-/-)$ knockout mice show an induction of antioxidant enzymes and GSTs alpha-1/alpha-2 (A1/A2), mu-1 (M1), and mu-5 (M5), as well as an increase in the ratio of oxidized glutathione (GSSG) to GSH, suggesting that GSTZ1 deficiency causes oxidative stress (Lim et al., 2004; Blackburn et al., 2006). GSTZ1(-/-) mice also demonstrated induction of $\mathrm{NAD}(\mathrm{P}) \mathrm{H}$ dehydrogenase [quinone] 1 (NQO1) and lethality in young mice after the inclusion of phenylalanine, a precursor of tyrosine, in drinking water (Lim et al., 2004). In this study, we determined if loss of the expression and activity of GSTZ1 in rat tissues after multiple DCA dosages that mimicked therapy resulted in similar effects. We hypothesized that the DCA-mediated downregulation of GSTZ1 causes oxidative stress through increased maleylacetone and reactive oxygen species. We used a rat model to assess the induction of hepatic GSTs and antioxidant enzymes after repeated administration of a "therapeutic" dose of DCA to juvenile (4-week) and adult (52-week) Sprague Dawley rats, which have been used in previous work to study the neurotoxic effects of DCA (Calcutt et al., 2009).

\section{Materials and Methods}

Chemicals, Animals, and Reagents. Four-week-old and 52-week-old female and male Sprague Dawley rats were purchased from Charles River Laboratories (Wilmington, MA) and approved for use by the University of Florida Institutional Animal Care and Use Committee. We obtained the antibodies to GSTM1 and GSTP1 from Invitrogen (Carlsbad, CA), antibody to GSTA1/A2 from MilliporeSigma (Burlington, MA), and antibody to GSTO1 from Cusabio (Houston, TX). Antibodies to gamma-glutamylcysteine ligase complex (GCLC) and glutathione synthetase (GSS) were purchased from Proteintech (Rosemont, IL); the antibody to NQO1 was acquired from Abcam (Cambridge, UK). TransBlot Turbo nitrocellulose RTA Transfer Kit, TGX Stain-free FastCast 12\% Acrylamide kit, Clarity Western ECL Substrate reagent, 10X Tris/Glycine/SDS Buffer, Blotting-grade blocker nonfat dry milk, and Precision Plus Protein Dual Color Standards were purchased from Bio-rad Laboratories (Hercules, CA). We acquired 1,2-dichloro-4-nitrobenzene (DCNB), 1-chloro-2,4-dinitrobenzene (CDNB), 2,6-dichlorophenolindophenol (DCPIP), 7-chloro-4-nitrobenzo-2-oxa1,3-diazole (NBD-Cl), NADPH, dicoumarol, GSH, and anti-rabbit horseradish peroxidase secondary antibody from Sigma Aldrich (St Louis, MO). The Pierce BCA Protein Assay Kit was purchased from Thermofisher Scientific (Waltham, MA). Costar Spin X nylon centrifuge filters, $0.2 \mu \mathrm{m}$, were from Corning
Instruments (Corning, NY). Immunoblots were visualized using ChemiDoc Imaging System from Bio-rad Laboratories. Ponceau S was obtained from Alfa Aesar (Havervill, MA). UV studies were conducted using a Shimadzu dual-beam UV-2700 spectrophotometer (Kyoto, Japan). High-performance liquid chromatography-grade ammonium formate, formic acid, methanol, trichloroacetic acid, EDTA, butylated hydroxytoluene, GSSG,${ }^{13} \mathrm{C}-\mathrm{GSH}$, Optima LC/MS grade water, and all other reagents were purchased from commercial suppliers.

Rodent Dosing and Preparation of Hepatic Cytosol. Young male and female (4-week) and adult female (52-week) Sprague Dawley rats were dosed with sodium acetate $(100 \mathrm{mg} / \mathrm{kg})$ or sodium DCA $(100 \mathrm{mg} / \mathrm{kg})$ by oral gavage daily for eight consecutive days in groups of four to eight animals per treatment. On the ninth day ( 24 hours after the last dose), the rats were euthanized with carbon dioxide, and livers were removed and processed into cytosolic subcellular fractions as previously described ( $\mathrm{Li}$ et al., 2011). This study used a treatment period of 8 days because steady-state reduction in GSTZ1 is achieved within 5-7 days (Schultz and Sylvester, 2001; Saghir and Schultz, 2005; Shroads et al., 2012). We were interested in the effects of DCA between age groups and, therefore, used 4- and 52-week-old rats to model children and adults around the ages of 2 and 30 years, respectively (Quinn, 2005). The rat DCA dose of $100 \mathrm{mg} / \mathrm{kg}$ was chosen as it is therapeutically similar to the human DCA dose of $25 \mathrm{mg} / \mathrm{kg}$ per day by species scaling (Boxenbaum, 1980). Sodium acetate was chosen as control as is it structurally similar to DCA and was previously shown to have no effect on GSTZ1 (Jahn et al., 2018; Smeltz et al., 2019).

GST Activity Assays with CDNB and DCNB as Substrates. GST activities with CDNB and DCNB were measured at $37^{\circ} \mathrm{C}$ as described below. Each reaction contained $100 \mathrm{mM}$ HEPES pH 7.6, $1 \mathrm{mM} \mathrm{GSH}$, and varied concentrations of CDNB $(0.10-1.0 \mathrm{mM})$ or DCNB $(0.25-3.0 \mathrm{mM})$ in a final reaction volume of 3.0 $\mathrm{ml}$. CDNB reactions were initiated by the addition of protein $(10 \mu \mathrm{g})$ and proceeded for 75 seconds, whereas DCNB reactions used $1.0 \mathrm{mg}$ protein for an incubation time of 2 minutes. The GST-catalyzed glutathione conjugates of $\mathrm{CDNB}$ and DCNB were recorded at $344 \mathrm{~nm}$ and corrected for the nonenzymatic reaction, using a blank appropriate to the substrate used. Calculation of specific activity was based on 9.6 and $8.5 \mathrm{mM}^{-1} \mathrm{~cm}^{-1}$ as molar extinction coefficients for the glutathione conjugates of CDNB and DCNB, respectively (Habig et al., 1974). GST activity is defined as nanomoles product formed per minute per milligram protein. Data points are the means \pm S.D.s of duplicate determinations.

GST Activity Assay with Ethacrynic Acid as Substrate. The assay of ethacrynic acid was performed as follows. Each reaction contained $100 \mathrm{mM}$ sodium phosphate $\mathrm{pH} 6.5,1 \mathrm{mM} \mathrm{GSH}$, and $1 \mathrm{mM}$ ethacrynate sodium salt in a final reaction volume of $2.5 \mathrm{ml}$. The reactions were initiated by the addition of protein $(50 \mu \mathrm{g})$ for a 2 -minute incubation at $37^{\circ} \mathrm{C}$. The GST-catalyzed glutathione conjugation of ethacrynic acid was recorded at $270 \mathrm{~nm}$ and corrected for the nonenzymatic reaction using a blank, which was freshly prepared for each individual determination. Calculation of specific activity (nanomoles per minute per milligram) was based on $5.0 \mathrm{mM}^{-1} \mathrm{~cm}^{-1}$ as the molar extinction coefficient for the glutathione conjugate of ethacrynic acid (Habig et al., 1974).

NQO1 Activity Assay with DCPIP as Substrate. Protein incubations with DCPIP were performed at $25^{\circ} \mathrm{C}$, according to previous procedures (De Haan et al., 2002; Cabello et al., 2011). Each $1.0 \mathrm{ml}$ reaction contained $25 \mathrm{mM}$ Tris-HCl pH 7.4, $0.2 \mathrm{mg} / \mathrm{ml}$ BSA, $0.01 \%$ (v/v) Tween 20, $180 \mu \mathrm{M}$ NADPH, $40 \mu \mathrm{M}$ DCPIP (prepared in DMSO), $5 \mu \mathrm{g}$ liver cytosol protein, and 0 or $20 \mu \mathrm{M}$ dicoumarol, as appropriate. The reactions were initiated by the addition of DCPIP and proceeded for 2 minutes in the presence and absence of dicoumarol, where the reduction of DCPIP at $600 \mathrm{~nm}$ was recorded. Enzyme activity (nanomoles per minute per milligram protein) was calculated based on $20.7 \mathrm{mM}^{-1} \mathrm{~cm}^{-1}$ as the molar extinction coefficient of DCPIP (Hägerhäll et al., 1992). Data are means \pm S.D.s of duplicate determinations.

Western Blotting. Protein expression was assessed by Western blot using antibodies to alpha (A), mu (M), pi (P), and omega (O) class GSTs, and to NQO1, GCLC, and GSS. Known amounts of protein were separated by SDS-PAGE and then transferred to nitrocellulose membranes. The membranes were blocked for 1 hour at room temperature in 5\% milk prepared in TBST $(1 \times$ Tris-buffered saline containing $0.05 \%$ Tween 20 ). Afterward, the membranes were probed overnight at $4{ }^{\circ} \mathrm{C}$ using the following dilutions of primary antibody in 5\% milk: GSTZ1 (1:10,000), GSTA1/A2 (1:20,000), GSTM1 (1:5000), GSTP1 (1:1000), GSTO1 (1:4000), NQO1 (1:40,000), GCLC (1:5000), and GSS (1:5000). On the following morning and at room temperature, the membranes were washed for 30 minutes in TBST (buffer changed every 5 minutes), incubated for 1 hour in anti-rabbit 
TABLE 1

Kinetic constants for the GST-catalyzed reaction of CDNB and DCNB in rat liver cytosol

GST activity measurements were carried out at $37^{\circ} \mathrm{C}$, using $10 \mu \mathrm{g}$ protein for CDNB and $1 \mathrm{mg}$ protein for DCNB. Each reaction used $1 \mathrm{mM}$ GSH in the presence of varied substrate concentrations.

\begin{tabular}{|c|c|c|c|c|c|}
\hline \multirow{2}{*}{ Substrate } & \multirow{2}{*}{ Rat age, sex } & \multicolumn{2}{|c|}{$100 \mathrm{mg} / \mathrm{kg}$ sodium acetate } & \multicolumn{2}{|c|}{$100 \mathrm{mg} / \mathrm{kg}$ sodium DCA } \\
\hline & & $\mathrm{K}_{\mathrm{m}}$ & $\mathrm{V}_{\max }$ & $\mathrm{K}_{\mathrm{m}}$ & $\mathrm{V}_{\max }$ \\
\hline & & $\mathrm{mM}$ & $\mathrm{nmol} / \mathrm{min}$ per milligram & $\mathrm{mM}$ & $\mathrm{nmol} /$ min per milligram \\
\hline \multirow[t]{3}{*}{ CDNB } & Young female & $0.33 \pm 0.18$ & $4568 \pm 2801$ & $0.25 \pm 0.20$ & $7205 \pm 2808 * *$ \\
\hline & Young male & $0.22 \pm 0.08$ & $3724 \pm 956$ & $0.37 \pm 0.22$ & $8506 \pm 2258 * *$ \\
\hline & Adult female & $0.28 \pm 0.03$ & $4165 \pm 813$ & $0.20 \pm 0.02 * * * *$ & $5182 \pm 1213$ \\
\hline \multirow[t]{3}{*}{ DCNB } & Young female & $0.52 \pm 0.05$ & $59 \pm 13$ & $0.48 \pm 0.04$ & $104 \pm 12 * *$ \\
\hline & Young male & $0.49 \pm 0.09$ & $74 \pm 3$ & $0.51 \pm 0.09$ & $98 \pm 6^{* *}$ \\
\hline & Adult female & $0.56 \pm 0.07$ & $29 \pm 5$ & $0.55 \pm 0.05$ & $64 \pm 8^{* * *}$ \\
\hline
\end{tabular}

The data are expressed as the means \pm S.D.s of duplicate determinations from four (young) to eight (adult) independent experiments. Multiple comparisons showed DCNB $\mathrm{V}_{\text {max }}$ values were significantly

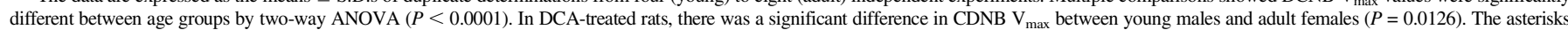
denote statistical significance when compared with the same kinetic parameter in acetate-treated controls: $* * P<0.01$; *** $P<0.001$; ****P<0.0001 (two-tailed Student's $t$ test).

secondary horseradish peroxidase antibody (1:5000), and washed again in TBST, as described above. Membranes were developed in Clarity Western ECL Substrate reagent prepared from one part luminol/enhancer solution, one part peroxide solution, and five parts water. Protein bands were visualized using the Chemi Doc imaging system, where the chemiluminescent signals for each band were normalized to a cytosolic reference sample. Protein loading was then verified by Ponceau-S staining. The relative expression (\%) is reported as the means \pm S.D.s of duplicate determinations.

Determination of GSH and GSSG Content. GSH and GSSG concentrations were measured from whole liver sections as described before (Smeltz et al., 2019) by modifying a previously published liquid chromatography-mass spectrometry (LC-MS) procedure (Squellerio et al., 2012). Briefly, rat liver tissues samples (75-100 mg) were homogenized for $5-10$ minutes in a $400 \mu l$ solution containing $10 \%$ trichloroacetic acid, $1 \mathrm{mM}$ EDTA, and $1 \mathrm{mM}$ butylated hydroxytoluene in a $1.7 \mathrm{ml}$ microcentrifuge tube. Ten microliters of a $1 \mu \mathrm{M}$ solution of ${ }^{13} \mathrm{C}-\mathrm{GSH}$ internal standard were added to each tube, mixed, and centrifuged 10 minutes to precipitate protein. A $200 \mu \mathrm{l}$ aliquot of the supernatant was removed and placed onto a $0.2 \mu \mathrm{m}$ Spin $X$ microcentrifuge tube filter. The samples were centrifuged for 10 minutes and the filtrate transferred to a $400 \mu l$ glass insert fitted in an amber $1.5 \mathrm{ml}$ autosampler vial. The LC-MS instrumentation was comprised of a Thermo Scientific TSQ Quantum Access Max mass spectrometer, a Thermo Scientific Accela 1250 pump, and a Thermo Scientific Accela open Pal autosampler. A Phenomenex Luna PFP high-performance liquid chromatography column $(150 \times$ $3 \mathrm{~mm}, 5 \mu \mathrm{m}$ ) was used. LC-MS control, data acquisition, and data processing were performed using Xcalibur version 2.1 software. All samples were maintained in a temperature-controlled autosampler at $4^{\circ} \mathrm{C}$ during the analysis. Results were calculated as millimoles of GSH or GSSG per kg liver tissue, i.e., millimolars.

Data Analysis. Data transformation and the calculation of means, S.D., and statistical significance were performed using GraphPad Prism 6 software (San Diego, CA). For initial velocity studies, data were fitted to a Michaelis-Menten equation to determine the Michaelis constant $\left(\mathrm{K}_{\mathrm{m}}\right)$ and maximal velocity $\left(\mathrm{V}_{\max }\right)$. Group comparisons were performed using a two-tailed Student's $t$ test (corrected for multiplicity by the Holm-Sidak method) or a two-way ANOVA. Statistical significance was defined as $P<0.05$.

\section{Results}

DCA Dosing in Rats Increases Hepatic Expression of GSTs A1/ A2, M1, and O1. GST activity in hepatic cytosol of acetate- and DCAtreated Sprague-Dawley rats was examined using CDNB and DCNB as substrates. CDNB is a nonselective substrate for multiple GST isoforms, including alpha, mu, and pi class GSTs (Ricci et al., 1994), whereas DCNB is catalyzed primarily by GST mu (Ioannides, 2001; Fujimoto et al., 2006; Arakawa et al., 2010). Ethacrynic acid and NBD-Cl were also examined as substrates, which are selective for GST pi (Ploemen et al., 1994) and GST alpha (Ricci et al., 1994), respectively. However, we were unable to obtain reliable kinetics with NBD-Cl due to its rapid nonenzymatic conjugation with glutathione (data not shown).
Initial velocities for the GST-catalyzed reactions of CDNB and DCNB are shown in Supplemental Figures 1 and 2; the maximal velocity $\left(\mathrm{V}_{\max }\right)$ and Michaelis-Menten constant $\left(\mathrm{K}_{\mathrm{m}}\right)$ are reported in Table 1. In comparison with acetate-treated controls, GST activities with DCNB were significantly higher in hepatic cytosol of DCA-treated rats, as indicated by $\mathrm{V}_{\max }$ (Table 1 ). In juveniles, DCA dosing increased activity with CDNB $(P<0.01)$, although a significant effect in adults was not observed $(P=0.069)$. It should be noted, however, that activity at a single concentration of CDNB (1.0 mM) in adults was higher in DCAtreated rats $(4483 \pm 1032 \mathrm{nmol} / \mathrm{min}$ per milligram, \pm S.D. $)$ than in controls $(3408 \pm 739 \mathrm{nmol} / \mathrm{min}$ per milligram, $P<0.05)$. Additionally, a lower $\mathrm{K}_{\mathrm{m}}$ value was observed in DCA-treated adults when CDNB was used as substrate $(P<0.0001)$.

Subsequently, we examined the relative expression of GST isoforms in hepatic cytosol of acetate- and DCA-treated rats. Initial data were obtained using antibodies to GSTs A1/A2, M1, and P1, as they are the most abundant mammalian GSTs (Hayes and Pulford, 1995). A depiction of the knockdown of GSTZ1 protein expression and induction of antioxidant enzymes is shown in Figure 1; we include a representative blot showing the detection of chemiluminescent signals and total protein staining by Ponceau-S in Supplemental Figure 3. Our Western blot

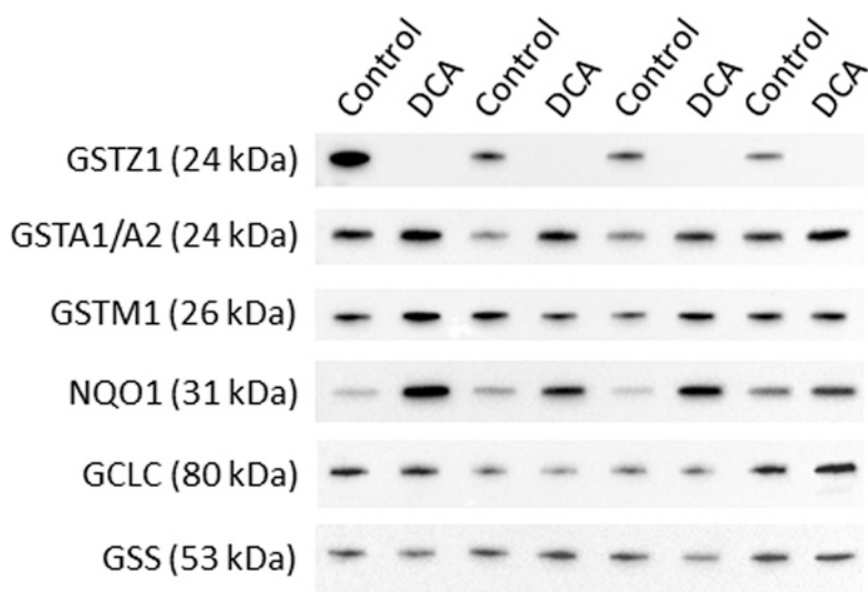

Fig. 1. Western blot showing GSTZ1 downregulation and induction of antioxidant proteins in hepatic cytosol of 4-week-old male Sprague Dawley rats that were given eight daily oral doses of $100 \mathrm{mg} / \mathrm{kg}$ sodium acetate (control) or $100 \mathrm{mg} / \mathrm{kg}$ sodium DCA. Blots were probed using antibodies to rat GSTZ1, GSTA1/A2, GSTM1, NQO1, GCLC, and GSS. Each lane shows results for cytosol from a different individual control or DCA-treated rat. Each row was loaded with the same amount of protein per lane. This was $2 \mu \mathrm{g}$ for GSTZ1 and GSTA1/2, $5 \mu \mathrm{g}$ for GSTM1, 15 $\mu \mathrm{g}$ for GCLC and GSS, and $20 \mu \mathrm{g}$ for NQO1. 
analyses showed the expression of GSTA1/A2 was higher in liver cytosol of DCA-treated rats irrespective of rodent age or sex (Fig. 2, A and B). DCA dosing increased the expression of GSTs M1 and O1 in adult rats $(P<0.05)$, whereas the effect on M1 in juveniles was not significant $(P \geq 0.08)$. GSTO1 expression was not examined in juveniles due to limited antisera. Lastly, DCA dosing did not influence the expression of GSTP1 in either rodent group (data not shown), nor

A

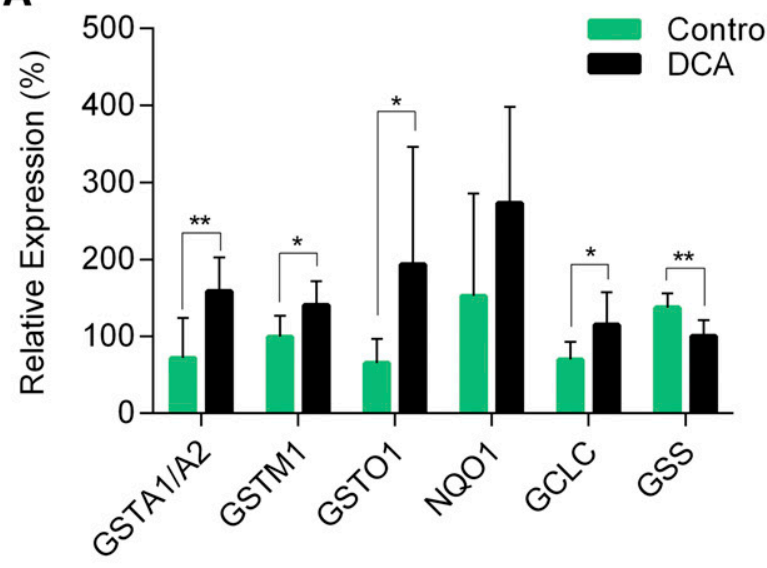

B $\quad$ Control

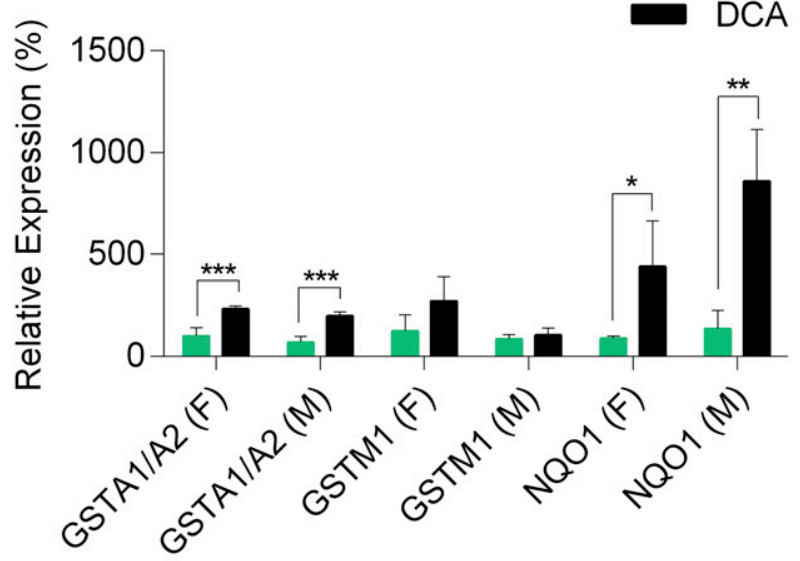

C

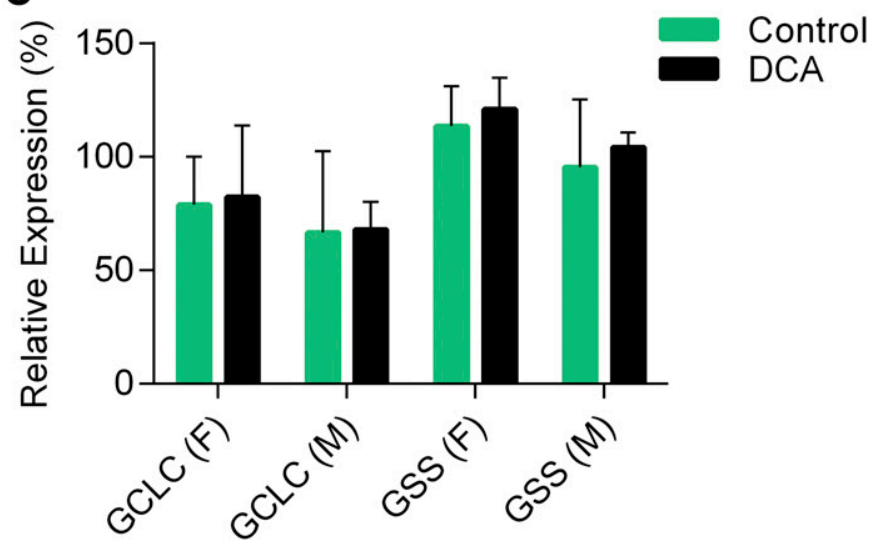

Fig. 2. Relative expression of GSTs and antioxidant enzymes in hepatic cytosol of adult (A) and young (B and C) rats that received eight daily oral doses of $100 \mathrm{mg} / \mathrm{kg}$ sodium acetate (control) or $100 \mathrm{mg} / \mathrm{kg}$ sodium DCA as determined by Western blot. Male and female sexes are denoted by "M" and "F," respectively. Data are means \pm S.D.s of duplicate determinations from four to eight independent experiments. $* * * P<0.001 ; * * P<0.01 ; * P<0.05$. were there differences in GSTP1 activity between groups when examined with ethacrynic acid as substrate (data not shown).

DCA Dosing Increases Hepatic Expression and Activity of NQO1 in Juvenile, but Not in Adult, Rats. Table 2 summarizes activities for the NQO1-catalyzed reduction of DCPIP in rat liver cytosol. In comparison with acetate-treated controls, DCA dosing in juveniles resulted in a significant increase in NQO1 activity in males $(P<0.01$, Table 2$)$ but not in females $(P=0.06)$. However, there was a significant increase in NQO1 expression in DCA-treated juveniles irrespective of sex (Fig. 2B). We did not detect significant changes in NQO1 expression or activity between adult treatment groups (Fig. 2A).

Repetitive DCA Dosing Increases Hepatic GSH Levels in Adult but Not Juvenile Rats. We examined reduced (GSH) and oxidized (GSSG) glutathione concentrations in whole livers of young and adult rats dosed repetitively with $100 \mathrm{mg} / \mathrm{kg}$ sodium acetate (control) or $100 \mathrm{mg} / \mathrm{kg}$ sodium DCA. In addition, we examined the relative expression of GCLC and GSS, because of their importance in glutathione biosynthesis. Compared with controls, the molar concentration of GSH was significantly higher in livers of DCA-treated adults $(P<0.0001$, Table 3$)$, yet we did not detect differences in GSSG or the GSH:GSSG molar ratio. GCLC expression was higher in DCA-treated adults $(P<0.05$, Fig. 2A), consistent with the increase in GSH. GSS expression decreased after DCA treatment in adults $(P<0.01$, Fig. 2A). In young females, DCA did not significantly alter GSH, GSSG, or GSH:GSSG, nor did we detect changes in the expression of GCLC or GSS (Fig. 2C). Due to limited available tissue, our analysis of GSH and GSSG in young male controls was restricted to two samples; we report the untransformed values in Table 3.

Repetitive DCA Dosing Increases Liver Weights in Young and Adult Rats. The percent weight of the liver relative to total rodent body weight was examined. As shown in Figure 3, repeated administration of $100 \mathrm{mg} / \mathrm{kg}$ DCA to rats resulted in a significant increase in the liver to body weight ratio for juveniles only, as shown by ANOVA. The means \pm S.D. of liver to body weight ratios are as follows: adult females (3.22 \pm 0.36 for controls, $3.88 \pm 0.36$ for DCA, $P=0.053)$, young females (5.38 \pm 0.76 for controls, $6.50 \pm 0.31$ for DCA, $P=0.011$ ), young males $(5.59 \pm 0.49$ for controls, $6.57 \pm 0.19$ for DCA, $P=0.0045)$. Here, the magnitude of increase in liver weight was the same $(120 \%$ of the control liver) irrespective of age or sex.

\section{Discussion}

Due to the ability of DCA to inactivate GSTZ1 and perturb isomerization of MAA and MA, we aimed to examine the physiologic response to transient GSTZ1 downregulation that occurs from repetitive DCA exposure. The hypothesis that GSTs and antioxidant enzymes are induced in response to the DCA-mediated knockdown of GSTZ1 was based on several findings. First, GSTZ1 (-/-) knockout mice show elevated levels of alpha, mu, and pi class GSTs over wild-type mice (Lim et al., 2004). Second, GSTZ1 (-/-) knockout mice demonstrated upregulation of NQO1 and activation of Nrf2-mediated antioxidant response pathways (Blackburn et al., 2006). Third, GSTZ1 knockout in hepatoma cells decreased glutathione concentrations, resulting in activation of Keap1/Nrf2 (Li et al., 2019). These studies show oxidative stress responses are activated after genetic ablation of GSTZ1. Therefore, we predicted that the pharmacologic depletion of GSTZ1 by repetitive DCA dosing would produce similar effects. We found that repeated administration of DCA to 4-week-old (juvenile) and 52-week-old (adult) Sprague Dawley rats reduced the expression and activity of GSTZ1 in hepatic cytosol by $90 \%$; these findings are summarized in a companion paper. We extended the study in the current work to examine the expression and activity of antioxidant enzymes in liver cytosol of young 
TABLE 2

NQO1 activity measurements with DCPIP as substrate

NQO1 activities were determined at $25^{\circ} \mathrm{C}$ using $5 \mu$ g liver cytosol protein and a single concentration of DCPIP substrate $(40 \mu \mathrm{M})$.

\begin{tabular}{lcc}
\hline Age, sex of rat & $100 \mathrm{mg} / \mathrm{kg}$ sodium acetate & $100 \mathrm{mg} / \mathrm{kg}$ sodium DCA \\
\hline & $\mathrm{nmol} / \mathrm{min}$ per milligram & $\mathrm{nmol} / \mathrm{min}$ per milligram \\
Young female & $394 \pm 77$ & $1066 \pm 586$ \\
Young male & $323 \pm 128$ & $792 \pm 207^{* *}$ \\
Adult female & $522 \pm 295$ & $812 \pm 274$ \\
\hline
\end{tabular}

The data are expressed as the means \pm S.D.s of duplicate determinations from four (young) to eight independent experiments (adults). Asterisks denote statistical significance when compared with activity in acetate-treated controls: $* * P=0.0080$ (two-tailed Student's $t$ test). The difference in activity between young female treatment groups was not significant $(P=0.0633)$.

and adult rats that were administered eight daily oral doses of $100 \mathrm{mg} / \mathrm{kg}$ sodium DCA.

We detected increases in GST activity with DCNB and CDNB in DCA-treated rodents (Table 1) as well as increases in the expression of GSTs A1/A2, M1, and O1 (Fig. 2). Of the four GST isoforms examined, three were upregulated in DCA-treated adults (A1/A2, M1, O1), whereas, in juveniles, we detected overexpression of a single isoform (A1/A2). Given their catalytic diversity, the differential induction of GSTs between age groups could influence efficiency of the GST detoxication system. For example, GSTO1 catalyzes reactions that are different from other GSTs, including deglutathionylation (Menon and Board, 2013), reduction of toxic alpha-haloketones (Board and Anders, 2007), and reduction of dehydroascorbate (Whitbread et al., 2005). GSTO1 can accommodate larger substrates (Board et al., 2000), further distinguishing this class of GSTs. The alpha class GSTs constitute the bulk expression of glutathione transferases in normal liver (Rowe et al., 1997; Prabhu et al., 2004) and were shown here to be induced by DCA in both young and adult rats. Alpha class GSTs catalyze detoxication of a variety of electrophilic substrates and also reversibly bind endogenous molecules such as bilirubin and xenobiotics such as polycyclic aromatic hydrocarbons, thus their induction protects the liver against damage from electrophiles and potentially toxic chemicals.

NQO1 catalyzes the two-electron reduction of quinones and plays a major role in regulating oxidative stress (Ross and Siegel, 2017, 2018). Since NQO1 was elevated in GSTZ1-deficient mice (Blackburn et al., 2006), we wanted to assess whether expression and activity of NQO1 would be altered by DCA. Induction of NQO1 in DCA-treated rats was striking in juveniles (Fig. 1; Fig. 2B), but not adults (Fig. 2A). These findings were similar to the observations with GSTs, showing variability in the level of induction between young and adult rats. The differential induction of antioxidant enzymes could alter the capacity to mitigate oxidative stress, which might influence susceptibility to toxicity. This may have implications in the age-related side effect of chronic DCA therapy, as the detoxication of chemical stress may be more efficient in certain age groups. Our incubations with DCNB showed higher GST activity in juveniles than adults (Table 1). Furthermore, juveniles showed higher liver to body weight ratios than adult rats (Fig. 3). Given these observations, we predict the capacity for GSTcatalyzed detoxication in juveniles is more robust. This may play a role in the observed lower susceptibility of children compared with adults to the adverse effects of DCA.

One detriment to the induction of GSTs is the potential for increased drug metabolism, which could limit the effectiveness of some medications. For example, increased GSTP mRNA and GSTM protein has been detected in doxorubicin-resistance breast cancer cells that display a multidrug resistance phenotype (Wang et al., 1999). Here, increased GSTs result in reduced efficacy of the anticancer drug. Overexpression of certain GSTs in cancer cells has been associated with resistance to apoptotic cell death (Cumming et al., 2001; Gaté and Tew, 2001; Hayes et al., 2005), a mechanism that is exploited by many anticancer drugs, including DCA. Induction of GSTs could also increase toxicity of some drugs: for example, GSTP catalyzes the first step in the bioactivation of cisplatin to a nephrotoxicant (Townsend et al., 2009). In this example, increases in the expression of certain GSTs by DCA may increase susceptibility to drug-induced toxicity, a potential concern in the coadministration of cisplatin and DCA (Xue et al., 2012). Attention should therefore be given to the effects of DCA on the GST system.

Nrf2 promotes the transcriptional induction of genes encoded by antioxidant response elements and is essential in cellular adaptation to oxidative stress (Higgins et al., 2009; Bellezza et al., 2018). Antioxidant response element-directed genes produce a myriad of antioxidant proteins, including GSTs, NQO1, GCLC, and GSS (Shih et al., 2003; Hur and Gray, 2011). Nrf2 is stabilized by Keap1 (Itoh et al., 1999, 2003), which contains cysteine residues that are sensitive to oxidation by electrophilic molecules (Dinkova-Kostova et al., 2002). The induction of GSTs and NQO1 after repeated DCA dosing in rats is consistent with a mechanism involving Nrf2 activation, as accumulated MA, due to the DCA-mediated knockdown of GSTZ1, could lead to alkylation of Keap1. This would dissociate Nrf2 from Keap1, resulting in gene transcription. We did not examine MA and MAA levels in the current report. However, elevated levels of MA were previously detected in plasma and urine of rats that received DCA at a lower dose $(50 \mathrm{mg} / \mathrm{kg})$ for a shorter treatment time (5 days) (Shroads et al., 2008) and in humans chronically exposed to DCA (Stacpoole et al., 2006). Additionally, MA was excreted in the urine of rats that received DCA in drinking water for 8 weeks at $50 \mathrm{mg} / \mathrm{kg}$ (Guo et al., 2006). Another possible explanation of observations in the current report could relate to DCA's mechanism of action. DCA inhibits PDK to maintain PDC in its unphosphorylated, active form (James et al., 2017; Stacpoole et al., 2019), yet the targeted inhibition of PDK increases mitochondrial reactive oxygen species (ROS) in cancer and, possibly, other cells (Kankotia and Stacpoole, 2014). In fact, the apoptotic and antiproliferative effects of DCA in certain cancer cells are due, in part, to the utilization of ROS that it

TABLE 3

Summary of GSH and GSSG levels, millimoles per kilogram, in whole livers of acetate- (control) and DCA-treated rats

\begin{tabular}{|c|c|c|c|c|c|c|}
\hline \multirow{2}{*}{ Age, sex of rat } & \multicolumn{2}{|c|}{ GSH (mM) } & \multicolumn{2}{|c|}{ GSSG (mM) } & \multicolumn{2}{|c|}{ GSH:GSSG } \\
\hline & Control & DCA & Control & DCA & Control & DCA \\
\hline Young female $^{a}$ & $4.67 \pm 0.41$ & $5.63 \pm 1.62$ & $0.14 \pm 0.05$ & $0.17 \pm 0.09$ & $36.00 \pm 8.30$ & $39.72 \pm 14.5$ \\
\hline Young male $^{a}$ & $4.19 ; 6.62^{b}$ & $6.39 \pm 1.03$ & $0.17 ; 0.17^{b}$ & $0.19 \pm 0.06$ & $25.21 ; 39.17^{b}$ & $34.78 \pm 5.07$ \\
\hline Adult female ${ }^{c}$ & $5.59 \pm 0.48^{d}$ & $7.05 \pm 0.39^{d}$ & $0.21 \pm 0.06$ & $0.28 \pm 0.08$ & $27.82 \pm 7.76$ & $27.13 \pm 9.41$ \\
\hline
\end{tabular}

${ }^{a}$ Mean \pm S.D. $(n=4)$.

${ }^{b}$ Individual values reported from two determinations.

${ }^{c}$ Mean \pm S.D. $(n=8)$.

${ }^{d} P<0.0001$ control vs. DCA-treated (two-tailed Student's $t$ test). 


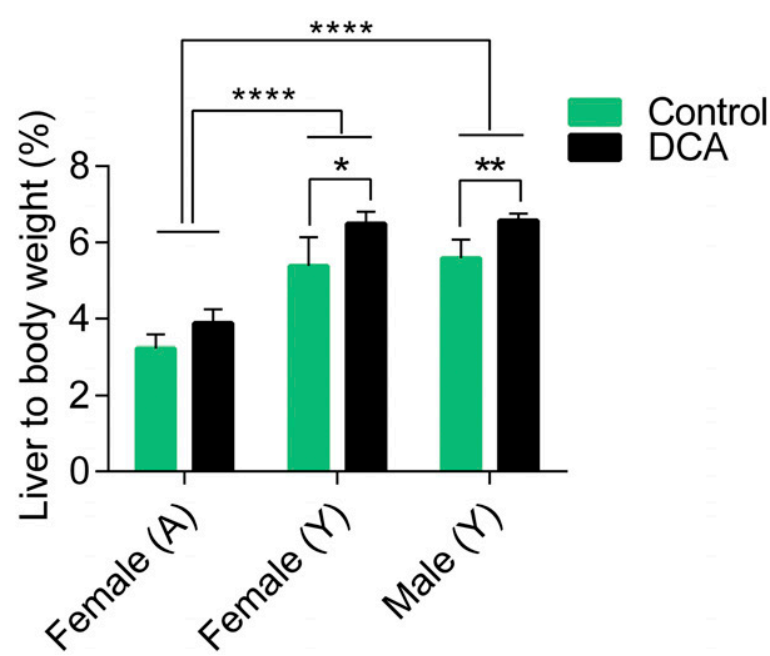

Fig. 3. Proportion of liver to total body weight in rats that received eight daily oral doses of $100 \mathrm{mg} / \mathrm{kg}$ sodium acetate (control) or $100 \mathrm{mg} / \mathrm{kg}$ sodium DCA. Young and adult rats are denoted by "Y" and "A," respectively. Data are the means \pm S.D.s of four or eight replicates. There was a significance difference between age groups by two-way ANOVA **** $(P<0.0001)$. Comparison of treatment groups by two-way ANOVA resulted in $P$ values of $0.0527,0.0106(*)$, and $0.0045(* *)$, respectively, for adult females, young females, and young males.

produces (Michelakis et al., 2008; Sanchez et al., 2013; Dai et al., 2014). This suggests DCA alone may trigger oxidative stress, which could underlie its neurotoxicity.

DCA dosing increased the relative liver weights of young rats (Fig. 3). Liver weights in adult rats were not significantly increased $(P=0.053)$, but the data suggested a trend. Several studies in rodents show that DCA is a peroxisome proliferator and induces activation of peroxisome proliferator-activated receptor alpha (PPAR $\alpha$ ) (IARC Working Group on the Evaluation of Carcinogenic Risks to Humans, 2014). Activation of PPAR $\alpha$ in liver can contribute to liver enlargement (Hall et al., 2012) and may explain the current observations. However, cultured human hepatocytes showed little to no activation of the endogenous human PPAR $\alpha$ by peroxisome proliferators (Walgren et al., 2000), suggesting this mechanism may have little relevance to the effect of DCA on human liver in the context of hypertrophy, and there is no evidence that chronic DCA administration to humans exerts any change in liver function (Abdelmalak et al., 2013). Additional studies are needed to discern whether the observed liver weight increase in rodents is a species-specific phenomenon indicative of hepatotoxicity or an adaptive response to enzyme induction.

GSTZ1 (-/-) knockout mice show altered levels of GSH and GSSG relative to wild-type mice (Blackburn et al., 2006). Given the profound knockdown of GSTZ1 by DCA (Fig. 1 and companion paper), we assessed hepatic tissue for changes in GSH concentrations. Interestingly, DCA dosing increased the levels of GSH in adult rats but did not significantly change GSSG or the molar ratio (Table 3). The increase in GSH was consistent with the higher expression of GCLC (Fig. 2A), which catalyzes the rate-limiting step in GSH biosynthesis. Others reported GCLC was induced after DCA treatment in mice (Theodoratos et al., 2012) and speculated involvement of an ROS-independent mechanism instead of oxidative stress. Neither GCLC, GSS, GSH, GSSG, or GSH:GSSG was altered by DCA dosing in juveniles. This study showed an age-related effect by DCA on GSH concentrations and GSH-synthesizing enzymes.

In summary, we confirmed the induction of hepatic GSTs and antioxidant enzymes in rats that were given repeated, clinically relevant doses of DCA. These findings are consistent with the upregulation of detoxification enzymes previously demonstrated in GSTZ1-deficient mice (Lim et al.,
2004; Blackburn et al., 2006) and suggest that depletion of GSTZ1 by DCA produces a similar biologic response. The induction of distinct GSTs, NQO1, GCLC, and GSS varied between young and adult rats, suggesting that the antioxidant defense response between age groups is not uniform. This information will be useful when considering the use of DCA in combination with other drugs and provides new insight into factors that may contribute to the age-related toxic effect of DCA in humans.

\section{Acknowledgments}

We thank Marci G. Smeltz and Katherine Cisneros for their assistance in rodent tissue collection and preparation of subcellular fractions. We also thank Mayar T. Ibrihim Mohamed, Aude S. Laguerre, and Sashyel Altman for their assistance with enzymatic activity assays.

\section{Authorship Contributions}

Participated in research design: Squirewell, Stacpoole, James. Conducted experiments: Squirewell, Mareus, Horne, James.

Performed data analysis: Squirewell, Horne, Stacpoole, James.

Wrote or contributed to writing of the manuscript: Squirewell, Horne, Stacpoole, James.

\section{References}

Abdelmalak M, Lew A, Ramezani R, Shroads AL, Coats BS, Langaee T, Shankar MN, Neiberger RE, Subramony SH, and Stacpoole PW (2013) Long-term safety of dichloroacetate in congenital lactic acidosis. Mol Genet Metab 109:139-143.

Arakawa S, Maejima T, Kiyosawa N, Yamaguchi T, Shibaya Y, Aida Y, Kawai R, Fujimoto K, Manabe S, and Takasaki W (2010) Methemoglobinemia induced by 1,2-dichloro-4-nitrobenzene in mice with a disrupted glutathione S-transferase Mu 1 gene. Drug Metab Dispos 38:1545-1552.

Bellezza I, Giambanco I, Minelli A, and Donato R (2018) Nrf2-Keap1 signaling in oxidative and reductive stress. Biochim Biophys Acta Mol Cell Res 1865:721-733.

Blackburn AC, Matthaei KI, Lim C, Taylor MC, Cappello JY, Hayes JD, Anders MW, and Board PG (2006) Deficiency of glutathione transferase zeta causes oxidative stress and activation of antioxidant response pathways. Mol Pharmacol 69:650-657.

Blackburn AC, Woollatt E, Sutherland GR, and Board PG (1998) Characterization and chromosome location of the gene GSTZ1 encoding the human Zeta class glutathione transferase and maleylacetoacetate isomerase. Cytogenet Cell Genet 83:109-114.

Board PG and Anders MW (2007) Glutathione transferase omega 1 catalyzes the reduction of S(phenacyl)glutathiones to acetophenones. Chem Res Toxicol 20:149-154.

Board PG, Coggan M, Chelvanayagam G, Easteal S, Jermiin LS, Schulte GK, Danley DE, Hoth LR, Griffor MC, Kamath AV, et al. (2000) Identification, characterization, and crystal structure of the Omega class glutathione transferases. J Biol Chem 275:24798-24806.

Boxenbaum H (1980) Interspecies variation in liver weight, hepatic blood flow, and antipyrine intrinsic clearance: extrapolation of data to benzodiazepines and phenytoin. $J$ Pharmacokinet Biopharm 8:165-176.

Cabello CM, Lamore SD, Bair WB III, Davis AL, Azimian SM, and Wondrak GT (2011) DCPIP (2,6-dichlorophenolindophenol) as a genotype-directed redox chemotherapeutic targeting NQO1*2 breast carcinoma. Free Radic Res $\mathbf{4 5}: 276-292$.

Calcutt NA, Lopez VL, Bautista AD, Mizisin LM, Torres BR, Shroads AL, Mizisin AP, and Stacpoole PW (2009) Peripheral neuropathy in rats exposed to dichloroacetate. J Neuropathol Exp Neurol 68:985-993.

Cornett R, James MO, Henderson GN, Cheung J, Shroads AL, and Stacpoole PW (1999) Inhibition of glutathione S-transferase zeta and tyrosine metabolism by dichloroacetate: a potential unifying mechanism for its altered biotransformation and toxicity. Biochem Biophys Res Commun 262:752-756.

Cumming RC, Lightfoot J, Beard K, Youssoufian H, O'Brien PJ, and Buchwald M (2001) Fancon anemia group $\mathrm{C}$ protein prevents apoptosis in hematopoietic cells through redox regulation of GSTP1. Nat Med 7:814-820.

Dai Y, Xiong X, Huang G, Liu J, Sheng S, Wang H, and Qin W (2014) Dichloroacetate enhances adriamycin-induced hepatoma cell toxicity in vitro and in vivo by increasing reactive oxygen species levels. PLoS One 9:e92962.

De Haan LHJ, Boerboom AMJF, Rietjens IMCM, van Capelle D, De Ruijter AJM, Jaiswal AK, and Aarts JMMJG (2002) A physiological threshold for protection against menadione toxicity by human NAD(P)H:quinone oxidoreductase (NQO1) in Chinese hamster ovary (CHO) cells. Biochem Pharmacol 64:1597-1603.

Dinkova-Kostova AT, Holtzclaw WD, Cole RN, Itoh K, Wakabayashi N, Katoh Y, Yamamoto M, and Talalay P (2002) Direct evidence that sulfhydryl groups of Keap1 are the sensors regulating induction of phase 2 enzymes that protect against carcinogens and oxidants. Proc Natl Acad Sci USA 99:11908-11913.

Fujimoto K, Arakawa S, Shibaya Y, Miida H, Ando Y, Yasumo H, Hara A, Uchiyama M, Iwabuchi H, Takasaki W, et al. (2006) Characterization of phenotypes in Gstm1-null mice by cytosolic and in vivo metabolic studies using 1,2-dichloro-4-nitrobenzene. Drug Metab Dispos 34:1495-1501.

Gaté L and Tew KD (2001) Glutathione S-transferases as emerging therapeutic targets. Expert Opin Ther Targets 5:477-489.

Guo X, Dixit V, Liu H, Shroads AL, Henderson GN, James MO, and Stacpoole PW (2006) Inhibition and recovery of rat hepatic glutathione S-transferase zeta and alteration of tyrosine metabolism following dichloroacetate exposure and withdrawal. Drug Metab Dispos 34:36-42. Habig WH, Pabst MJ, and Jakoby WB (1974) Glutathione S-transferases. The first enzymatic step in mercapturic acid formation. J Biol Chem 249:7130-7139.

Hägerhäll C, Aasa R, von Wachenfeldt C, and Hederstedt L (1992) Two hemes in Bacillus subtilis succinate:menaquinone oxidoreductase (complex II). Biochemistry 31:7411-7421. 
Hall AP, Elcombe CR, Foster JR, Harada T, Kaufmann W, Knippel A, Küttler K, Malarkey DE, Maronpot RR, Nishikawa A, et al. (2012) Liver hypertrophy: a review of adaptive (adverse and non-adverse) changes--conclusions from the 3rd International ESTP Expert Workshop. Toxicol Pathol 40:971-994.

Hayes JD, Flanagan JU, and Jowsey IR (2005) Glutathione transferases. Annu Rev Pharmacol Toxicol 45:51-88.

Hayes JD and McLellan LI (1999) Glutathione and glutathione-dependent enzymes represent a coordinately regulated defence against oxidative stress. Free Radic Res 31:273-300.

Hayes JD and Pulford DJ (1995) The glutathione S-transferase supergene family: regulation of GST and the contribution of the isoenzymes to cancer chemoprotection and drug resistance. Crit Rev Biochem Mol Biol 30:445-600.

Higgins LG, Kelleher MO, Eggleston IM, Itoh K, Yamamoto M, and Hayes JD (2009) Transcription factor Nrf2 mediates an adaptive response to sulforaphane that protects fibroblasts in vitro against the cytotoxic effects of electrophiles, peroxides and redox-cycling agents. Toxicol Appl Pharmacol 237:267-280.

Hubatsch I, Ridderström M, and Mannervik B (1998) Human glutathione transferase A4-4: an alpha class enzyme with high catalytic efficiency in the conjugation of 4-hydroxynonenal and other genotoxic products of lipid peroxidation. Biochem J 330:175-179.

Hur W and Gray NS (2011) Small molecule modulators of antioxidant response pathway. Curr Opin Chem Biol 15:162-173.

IARC Working Group on the Evaluation of Carcinogenic Risks to Humans (2014) Trichloroethylene, tetrachloroethylene, and some other chlorinated agents. IARC Monogr Eval Carcinog Risks Hum 106:1-512.

Ioannides C (2001) Enzyme Systems that Metabolise Drugs and Other Xenobiotics, John Wiley \& Sons, Ltd, Chichester, UK

Itoh K, Wakabayashi N, Katoh Y, Ishii T, Igarashi K, Engel JD, and Yamamoto M (1999) Keap1 represses nuclear activation of antioxidant responsive elements by $\mathrm{Nrf} 2$ through binding to the amino-terminal Neh2 domain. Genes Dev 13:76-86.

Itoh K, Wakabayashi N, Katoh Y, Ishii T, O'Connor T, and Yamamoto M (2003) Keap1 regulates both cytoplasmic-nuclear shuttling and degradation of Nrf2 in response to electrophiles. Genes Cells 8:379-391.

Jahn SC, Smeltz MG, Hu Z, Rowland-Faux L, Zhong G, Lorenzo RJ, Cisneros KV, Stacpoole PW and James MO (2018) Regulation of dichloroacetate biotransformation in rat liver and extrahepatic tissues by GSTZ1 expression and chloride concentration. Biochem Pharmacol 152:236-243.

James MO, Jahn SC, Zhong G, Smeltz MG, Hu Z, and Stacpoole PW (2017) Therapeutic applications of dichloroacetate and the role of glutathione transferase zeta-1. Pharmacol Ther 170:166-180.

James MO and Stacpoole PW (2016) Pharmacogenetic considerations with dichloroacetate dosing. Pharmacogenomics 17:743-753.

Johansson AS and Mannervik B (2001) Human glutathione transferase A3-3, a highly efficient catalyst of double-bond isomerization in the biosynthetic pathway of steroid hormones. $J$ Biol Chem 276:33061-33065.

Kankotia S and Stacpoole PW (2014) Dichloroacetate and cancer: new home for an orphan drug? Biochim Biophys Acta 1846:617-629.

Kaufmann P, Engelstad K, Wei Y, Jhung S, Sano MC, Shungu DC, Millar WS, Hong X, Gooch CL, Mao X, et al. (2006) Dichloroacetate causes toxic neuropathy in MELAS: a randomized, controlled clinical trial. Neurology 66:324-330.

Laborde E (2010) Glutathione transferases as mediators of signaling pathways involved in cell proliferation and cell death. Cell Death Differ 17:1373-1380.

Lantum HBM, Cornejo J, Pierce RH, and Anders MW (2003) Perturbation of maleylacetoacetic acid metabolism in rats with dichloroacetic Acid-induced glutathione transferase zeta deficiency. Toxicol Sci 74:192-202.

Lantum HBM, Liebler DC, Board PG, and Anders MW (2002) Alkylation and inactivation of human glutathione transferase zeta (hGSTZ1-1) by maleylacetone and fumarylacetone. Chem Res Toxicol 15:707-716.

Li J, Wang Q, Yang Y, Lei C, Yang F, Liang L, Chen C, Xia J, Wang K, and Tang N (2019) GSTZ1 deficiency promotes hepatocellular carcinoma proliferation via activation of the KEAP1/ NRF2 pathway. J Exp Clin Cancer Res 38:438.

Li W, James MO, McKenzie SC, Calcutt NA, Liu C, and Stacpoole PW (2011) Mitochondrion as a novel site of dichloroacetate biotransformation by glutathione transferase zeta 1. J Pharmaco Exp Ther 336:87-94.

Lim CEL, Matthaei KI, Blackburn AC, Davis RP, Dahlstrom JE, Koina ME, Anders MW, and Board PG (2004) Mice deficient in glutathione transferase zeta/maleylacetoacetate isomerase exhibit a range of pathological changes and elevated expression of alpha, mu, and pi class glutathione transferases. Am J Pathol 165:679-693.

Mangal N, James MO, Stacpoole PW, and Schmidt S (2018) Model informed dose optimization of dichloroacetate for the treatment of congenital lactic acidosis in children. J Clin Pharmacol 58:212-220.

Menon D and Board PG (2013) A role for glutathione transferase Omega 1 (GSTO1-1) in the glutathionylation cycle. J Biol Chem 288:25769-25779.

Michelakis ED, Webster L, and Mackey JR (2008) Dichloroacetate (DCA) as a potential metabolictargeting therapy for cancer. Br J Cancer 99:989-994.

Pljesa-Ercegovac M, Savic-Radojevic A, Matic M, Coric V, Djukic T, Radic T, and Simic T (2018) Glutathione transferases: potential targets to overcome chemoresistance in solid tumors. In J Mol Sci 19:3785.

Ploemen JH, Van Schanke A, Van Ommen B, and Van Bladeren PJ (1994) Reversible conjugation of ethacrynic acid with glutathione and human glutathione S-transferase P1-1. Cancer Res $\mathbf{5 4}$ 915-919.

Prabhu KS, Reddy PV, Jones EC, Liken AD, and Reddy CC (2004) Characterization of a class alpha glutathione-S-transferase with glutathione peroxidase activity in human liver microsomes. Arch Biochem Biophys 424:72-80.

Quinn R (2005) Comparing rat's to human's age: how old is my rat in people years? Nutrition 21: 775-777.
Ricci G, Caccuri AM, Lo Bello M, Pastore A, Piemonte F, and Federici G (1994) Colorimetric and fluorometric assays of glutathione transferase based on 7-chloro-4-nitrobenzo-2-oxa-1,3-diazole. Anal Biochem 218:463-465.

Ross D and Siegel D (2017) Functions of NQO1 in cellular protection and coq10 metabolism and its potential role as a redox sensitive molecular switch. Front Physiol 8:595.

Ross D and Siegel D (2018) NQO1 in protection against oxidative stress. Curr Opin Toxicol 7 : $67-72$.

Rowe JD, Nieves E, and Listowsky I (1997) Subunit diversity and tissue distribution of human glutathione S-transferases: interpretations based on electrospray ionization-MS and peptide sequence-specific antisera. Biochem J 325:481-486.

Saghir SA and Schultz IR (2005) Toxicokinetics and oral bioavailability of halogenated acetic acids mixtures in naïve and GSTzeta-depleted rats. Toxicol Sci 84:214-224.

Sanchez WY, McGee SL, Connor T, Mottram B, Wilkinson A, Whitehead JP, Vuckovic S, and Catley L (2013) Dichloroacetate inhibits aerobic glycolysis in multiple myeloma cells and increases sensitivity to bortezomib. Br J Cancer 108:1624-1633.

Schultz IR and Sylvester SR (2001) Stereospecific toxicokinetics of bromochloro- and chlorofluoroacetate: effect of GST-zeta depletion. Toxicol Appl Pharmacol 175:104-113.

Shih AY, Johnson DA, Wong G, Kraft AD, Jiang L, Erb H, Johnson JA, and Murphy TH (2003) Coordinate regulation of glutathione biosynthesis and release by Nrf2-expressing glia potently protects neurons from oxidative stress. J Neurosci 23:3394-3406.

Shroads AL, Guo X, Dixit V, Liu H-P, James MO, and Stacpoole PW (2008) Age-dependent kinetics and metabolism of dichloroacetate: possible relevance to toxicity. J Pharmacol Exp Ther 324:1163-1171.

Shroads AL, Langaee T, Coats BS, Kurtz TL, Bullock JR, Weithorn D, Gong Y, Wagner DA, Ostrov DA, Johnson JA, et al. (2012) Human polymorphisms in the glutathione transferase zeta $1 /$ maleylacetoacetate isomerase gene influence the toxicokinetics of dichloroacetate. $J$ Clin Pharmacol 52:837-849.

Singh M, Kapoor A, and Bhatnagar A (2015) Oxidative and reductive metabolism of lipidperoxidation derived carbonyls. Chem Biol Interact 234:261-273.

Smeltz MG, Hu Z, Zhong G, Jahn SC, Rowland-Faux L, Horne LP, Stacpoole PW, and James MO (2019) Mitochondrial glutathione transferase zeta 1 is inactivated more rapidly by dichloroacetate than the cytosolic enzyme in adult and juvenile rat liver. Chem Res Toxicol 32: 2042-2052.

Squellerio I, Caruso D, Porro B, Veglia F, Tremoli E, and Cavalca V (2012) Direct glutathione quantification in human blood by LC-MS/MS: comparison with HPLC with electrochemical detection. J Pharm Biomed Anal 71:111-118

Stacpoole PW, Kerr DS, Barnes C, Bunch ST, Carney PR, Fennell EM, Felitsyn NM, Gilmore RL, Greer M, Henderson GN, et al. (2006) Controlled clinical trial of dichloroacetate for treatment of congenital lactic acidosis in children. Pediatrics 117:1519-1531.

Stacpoole PW, Martyniuk CJ, James MO, and Calcutt NA (2019) Dichloroacetate-induced peripheral neuropathy. Int Rev Neurobiol 145:211-238.

Stacpoole PW, Shuster J, Thompson JLPS, Prather RA, Lawson LA, Zou B, Buchsbaum R, and Nixon SJ (2018) Development of a novel observer reported outcome tool as the primary efficacy outcome measure for a rare disease randomized controlled trial. Mitochondrion 42:59-63.

Theodoratos A, Blackburn AC, Cappello J, Tummala P, Dahlstrom JE, and Board PG (2012) Dichloroacetic acid up-regulates hepatic glutathione synthesis via the induction of glutamatecysteine ligase. Biochem Pharmacol 83:427-433.

Tong Z, Board PG, and Anders MW (1998a) Glutathione transferase zeta catalyses the oxygenation of the carcinogen dichloroacetic acid to glyoxylic acid. Biochem J 331:371-374.

Tong Z, Board PG, and Anders MW (1998b) Glutathione transferase zeta-catalyzed biotransformation of dichloroacetic acid and other alpha-haloacids. Chem Res Toxicol 11: $1332-1338$.

Townsend DM and Tew KD (2003) The role of glutathione-S-transferase in anti-cancer drug resistance. Oncogene 22:7369-7375.

Townsend DM, Tew KD, He L, King JB, and Hanigan MH (2009) Role of glutathione S-transferase Pi in cisplatin-induced nephrotoxicity. Biomed Pharmacother 63:79-85.

Tzeng HF, Blackburn AC, Board PG, and Anders MW (2000) Polymorphism- and speciesdependent inactivation of glutathione transferase zeta by dichloroacetate. Chem Res Toxicol 13 : 231-236.

Walgren JE, Kurtz DT, and McMillan JM (2000) Expression of PPAR(alpha) in human hepatocytes and activation by trichloroacetate and dichloroacetate. Res Commun Mol Pathol Pharmacol 108:116-132.

Wang K, Ramji S, Bhathena A, Lee C, and Riddick DS (1999) Glutathione S-transferases in wildtype and doxorubicin-resistant MCF-7 human breast cancer cell lines. Xenobiotica 29:155-170

Whitbread AK, Masoumi A, Tetlow N, Schmuck E, Coggan M, and Board PG (2005) Characterization of the omega class of glutathione transferases, in Gluthione Transferases and GammaGlutamyl Transpeptidases (Sies H and Packer L eds) pp 78-99, Elsevier, New York.

Xue X, You S, Zhang Q, Wu Y, Zou G-Z, Wang PC, Zhao Y-L, Xu Y, Jia L, Zhang X, et al. (2012) Mitaplatin increases sensitivity of tumor cells to cisplatin by inducing mitochondrial dysfunction. Mol Pharm 9:634-644.

Yang Y, Cheng JZ, Singhal SS, Saini M, Pandya U, Awasthi S, and Awasthi YC (2001) Role of glutathione S-transferases in protection against lipid peroxidation. Overexpression of hGSTA2-2 in K562 cells protects against hydrogen peroxide-induced apoptosis and inhibits JNK and caspase 3 activation. J Biol Chem 276:19220-19230.

Address correspondence to: Dr. Margaret O. James, Department of Medicinal Chemistry, University of Florida College of Pharmacy, 1345 Center Drive, Gainesville, FL 32610. E-mail: mojames@ufl.edu 